\title{
$\mathrm{PH} 103$ acualidad
}

\section{La Red Ibérica en Defensa del Patrimonio Gráfico se moviliza por la conservación de la memoria urbana colectiva}

\begin{abstract}
Desde su fundación, en febrero de 2020, la Red Ibérica en Defensa del Patrimonio Gráfico, que aúna a diversos proyectos locales, tiene un objetivo global: salvaguardar y proteger toda la gráfica comercial de nuestras calles como patrimonio gráfico. El colectivo denuncia la amenaza de destrucción de este patrimonio a causa de las dinámicas de turistificación, gentrificación y el aplanamiento de la imagen de nuestras ciudades. La red propone ser una herramienta disponible y abierta para quien quiera defender su ciudad, una manera de poner en contacto a la población en general, administraciones y profesionales; en definitiva, un lugar de encuentro para todas las personas interesadas en las cuestiones urbanas, las vidas de sus barrios, sus memorias e identidades.
\end{abstract}

Alberto Nanclares da Veiga | Colectivo Paco Graco

URL de la contribución <http://www.iaph.es/revistaph/index.php/revistaph/article/view/4929>

Donde estuvo durante décadas la droguería Balius, en Poble Nou, hay un bar que Google maps define como "chic". La nueva dueña quiere conservar el rótulo, para preservar la memoria del negocio anterior, y contribuir también a la vida del barrio, cómo contribuyó aquel negocio, en principio más necesario que una coctelería. Ese cambio, estético, podría no ser un cambio social, tal vez los rótulos no sean testigos de la destrucción, sino que pueden ser palancas de cambio del cuidado urbano.

Donde está hoy en día el estudio fotográfico $\mathrm{Li}$, en el barrio de Usera, estuvo abierta un clínica dental durante 20 años, y antes de esa clínica, estuvo el taller mecánico que mi abuelo atendió durante más de 40 años en los bajos de la casa que él mismo construyó. ¿Cómo puede alguien que pasea ahora por esa calle conocer esa historia? ¿Qué trazos puede encontrar?

La gráfica comercial forma parte de la vida de las ciudades, tanto como las tiendas que sus rótulos anuncian: cuando un comercio de barrio cierra, se lleva sus historias y se rompen sus relaciones, se pierden décadas de memoria. Aunque la población en las ciudades está en constante cambio, y con ella los comercios que necesita, sabemos que los barrios necesitan bares, tintorerías y fruterías tanto como relojerías, tiendas de materiales de construcción, y tiendas de ropa interior donde se desa- rrolle la vida. Sabemos que no pueden vivir solo con franquicias de pan, cafés caros, pisos turísticos y restaurantes de lujo.

En abril de 2019 propusimos la idea de la Red Ibérica en Defensa del Patrimonio Gráfico al hilo del interés que despertó la muestra que el colectivo Paco Graco organizó en el Centro Cultural Casa del Reloj de Madrid: invitamos a los instagramers dedicados a documentar rótulos que conocíamos entonces, coleccionistas de cientos de

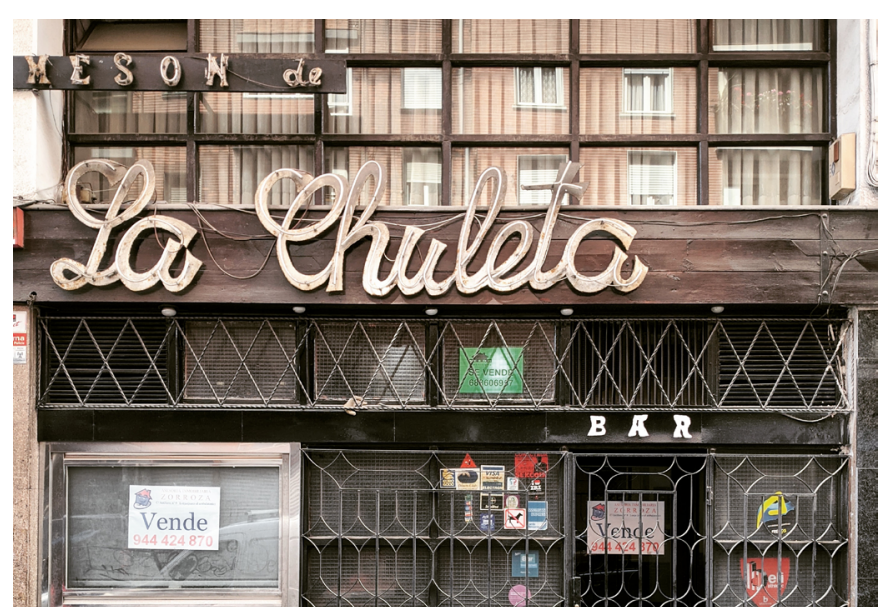

Restaurante La Chuleta, Bilbao | foto @Karramarrez, Red Ibérica en Defensa del Patrimonio Gráfico 
rótulos fotografiados con delicadeza a los que queríamos conocer en persona. La diferencia con ellos es que el colectivo Paco Graco decidió dar el paso al mundo físico, y ponerse a desmontar los rótulos antes de que desaparezcan. Recogemos rótulos físicamente desde 2014, cuando el final de la ley Boyer mandó al cierre a algunas de las tiendas y comercios más importantes de nuestras vidas. En estos dos años desde su fundación, la red ha crecido a muy buen ritmo, superando los 60 nodos involucrados activamente en ella, situados en más de 30 ciudades de la Península Ibérica, Canarias y Baleares. Entre esos nodos, colecciones físicas de rótulos "rescatados" van creciendo en lugares tan inesperados por nosotros como Linares y Jaén, dos plazas fuertes de la Red. El hashtag \#PatrimonioGráfico, inventado en aquel encuentro entre amigos en la clausura de la exposición de 2019 va desplegando su utilidad en diversas situaciones, y si bien es de libre uso, muchas de las cuentas que se fundan siguiendo el ejemplo de la Red dicen sentirse inspirados por él para dar sentido a su trabajo.

El nuestro no es un proyecto nostálgico o dedicado a la excelencia tipográfica; es un proyecto centrado en la construcción de memoria urbana colectiva, basándonos en el patrimonio gráfico. Es relativamente sencillo, hoy en día, encontrar buenos ejemplos de gráfica comercial a la venta en las tiendas de antigüedades. Esas letras sueltas no remiten en absoluto al comercio donde estuvieron expuestas; son un objeto sin memoria a partir del cual no podemos saber nada de la vida en la calle de la que algún día formaron parte. Hay, por su parte, muchos rótulos "populares" e "industriales" sin mucho valor "gráfico" intrínseco que son imprescindibles como parte de la memoria de la ciudad: este proyecto busca rótulos con historias que nos ayuden a comprender el presente.

Hay docenas de personas dedicadas a fotografíar y catalogar rótulos desde hace años: y aunque algunas colecciones permanecen inéditas, se han publicado no pocos libros brillantes al respecto. Curiosamente, las redes sociales han sido muy útiles para despertar el interés por el patrimonio entre los jóvenes. Paradojas de internet; nunca ha habido un mayor interés popular por el patrimonio que el que puede encontrarse en Instagram y Facebook. Las redes permiten además una presencia

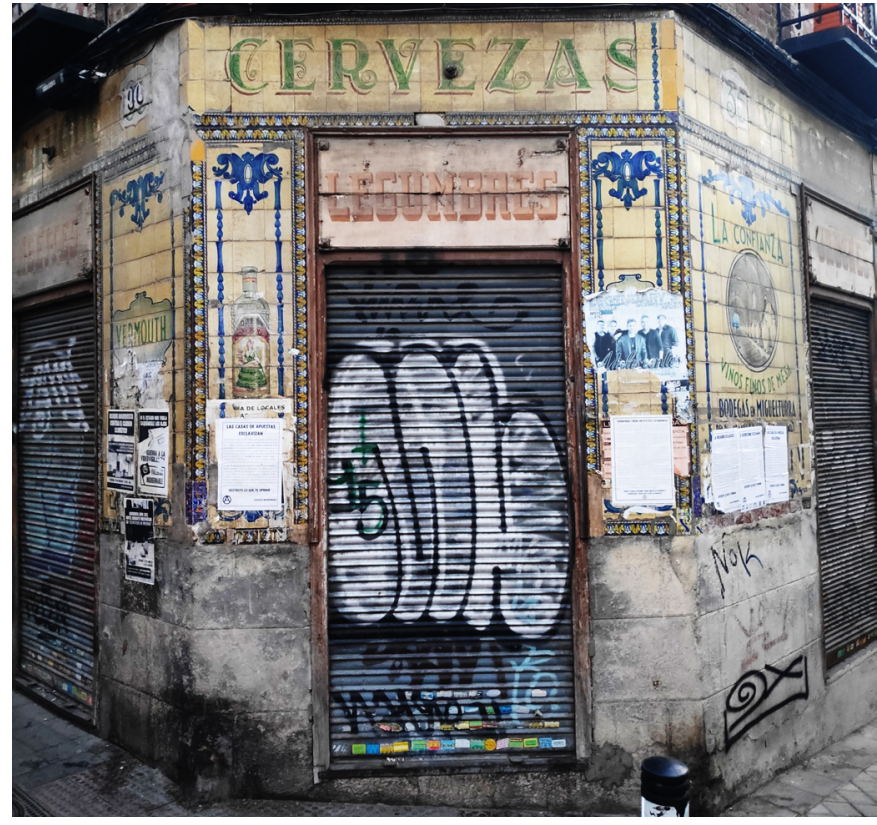

Comestibles Vinos José Luque, Vallecas, Madrid | foto @albertograco, Red Ibérica en Defensa del Patrimonio Gráfico

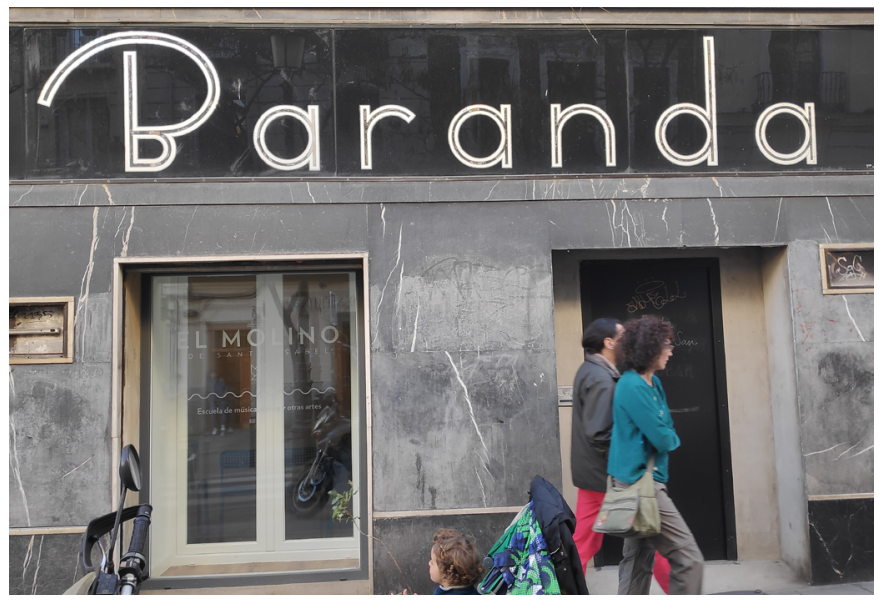

Curtidos Baranda, rótulo fuera de ordenanza, obligado a ser retirado por el Ayuntamiento de Madrid | foto Red Ibérica en Defensa del Patrimonio Gráfico

constante de gente en las calles atenta a todo lo que pasa: toda clase de detalles, anécdotas y elementos insignificantes tienen miles de cuentas en redes sociales dedicadas a ellas, que encuentran a su vez decenas de miles de seguidores. Sin embargo, este interés no encuentra respaldo por parte de las autoridades a la hora de proteger estos rótulos, o de considerarlos patrimonio. Aunque ha habido algunos esfuerzos tímidos recientes, en general la 


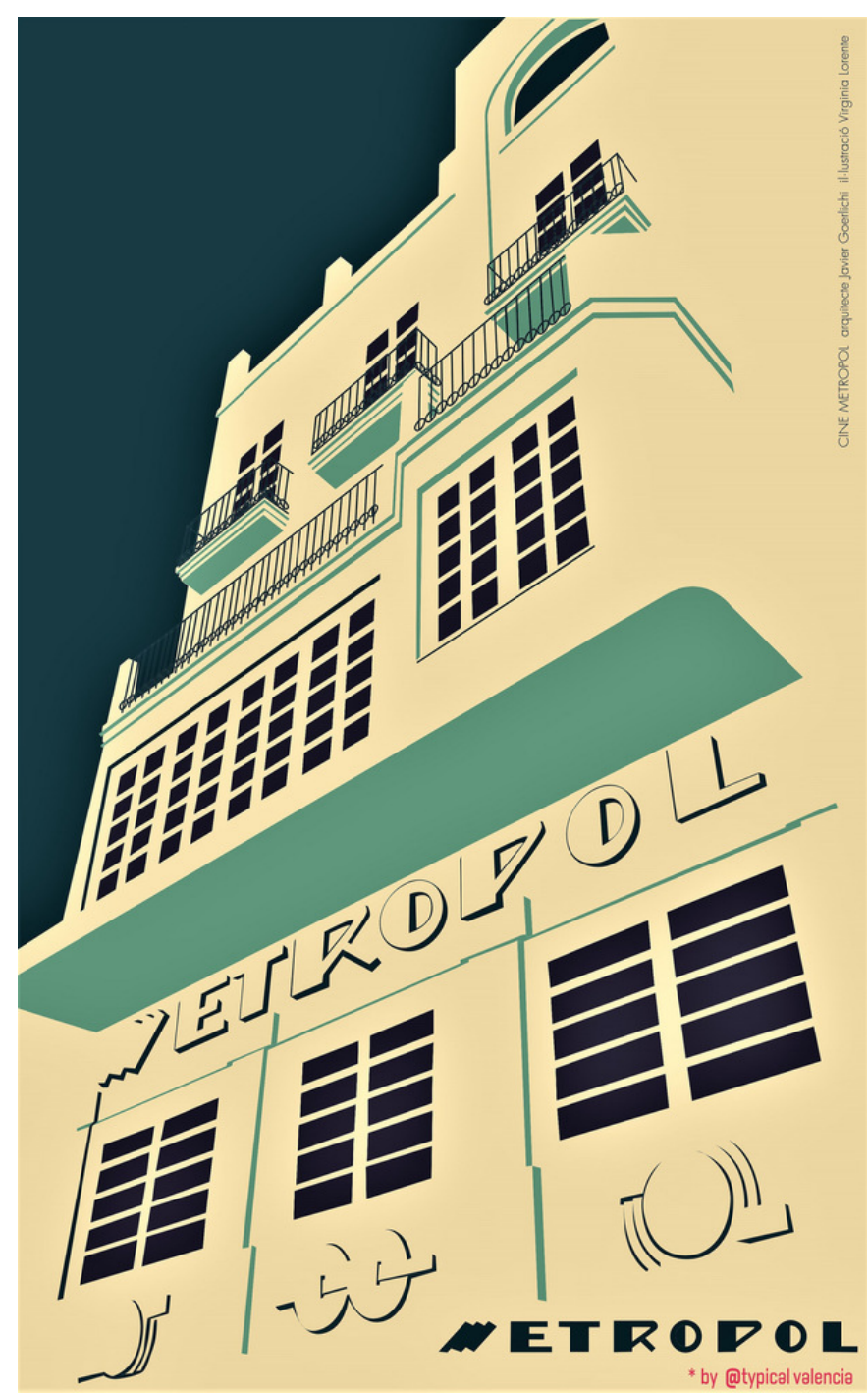

Ilustración del cine Metropol, rótulo que será derribado junto con todo el edificio en Valencia | ilustración Virgina Lorente-@typicalvalencia

catalogación de elementos protegidos ha dejado de lado los elementos de gráfica comercial. A menos que la presión popular los salve, en las próximas semanas veremos desaparecer de sus localizaciones dos ejemplos magníficos, no ya con la connivencia de los gobiernos locales, sino que tendrán que ser desmontados por orden de la autoridad competente. El cine Metropol de Valencia, cuya fachada de los años 30 no está protegida, y el rótulo de Curtidos Baranda, un rótulo doble pintado en dos épocas distintas en Madrid. Ambos son de estilo art decó, y su destrucción ha sido precedida en ambos casos por una larga e intensa lucha, por parte de los activistas y de los juristas, que ha terminado con la destrucción obligada, de modo que otro patrimonio protegido pueda prevalecer: en general el patrimonio arquitectónico "duro" (materiales pétreos) está protegido, pero los rótulos no. Además, las teorías "higienistas" persiguen los banderines (rótulos perpendiculares a la fachada), las marquesinas y en general todo rótulo que "afee el patrimonio". El principal desafío de la protección del patrimonio gráfico consiste hoy en día en ampliar la consciencia y valoración de los rótulos como una parte del patrimonio consustancial al patrimonio urbano, y no accesorio. El caso de Jaén es paradigmático: el Ayuntamiento quiere descongestionar visualmente el entorno de la catedral: ¿cómo separar el patrimonio "popular" (bares centenarios) del "patrimonio histórico" (patrimonios anteriores al siglo XX, de los que apenas quedan rótulos no pétreos) sin destruir la vida que generan esos paisajes?. Recientemente el COAVN (Colegio Oficial de Arquitectos Vasco-Navarro) pedían un consejo de patrimonio que "evite" el populismo. El rigor es tan necesario en la protección del patrimonio gráfico como en cualquier otro, pero tal vez cuando llegue no haya nada que proteger. No sería la primera vez que nos pasa.

El segundo principal reto para la defensa del patrimonio gráfico actual: viabilizar su protección antes de que las dinámicas actuales los destruyan: suponiendo que no falta interés, aún faltan herramientas detalladas y complejas que permitan avanzar en el palimpsesto que necesariamente tiene que ser el paisaje del entorno urbano, sin congelar la imagen de una ciudad en una determinada época (que se imponga sobre las otras), permitiendo a los usuarios actuales modificarlo tanto como sus antepasados, sin que precisamente esa sobrepoblación visual destruya el propio tejido visual y humano que se desarrolla en torno al patrimonio gráfico.

El reto más cercano (y más complicado) es hacer que la población valore el patrimonio gráfico de su barrio, así como el patrimonio del que muchos ciudadanos de a pie disponen. Razones de todo tipo se imponen para no conservar una fachada que a todas luces forma parte del paisaje de un barrio: comodidad, economía, claridad en el mensaje... Es relativamente fácil hacer convivir dos gráficas, y cuando se hace, suele ser un gran éxito. 